\title{
O professor da Educação de Jovens e Adultos (EJA) e o conhecimento educativo freireano
}

\section{The Education for Young People and Adults (EJA) teacher and the freirean educational knowledge}

\section{Maestro de la Educación de Jóvenes y Adultos (EJA) y educativo conocimiento freireano}

\author{
Ademar de Lima Carvalho ${ }^{1}$ \\ DOI: http://dx.doi.org/10.20435/serie-estudos.v23i47.1063
}

\begin{abstract}
Resumo: O presente artigo trata do resultado de uma investigação com 78 professores que atuam na Educação de Jovens e Adultos na rede pública no município de Rondonópolis, MT. A Investigação foi impulsionada pelo desejo de refletir sobre a prática pedagógica do professor. Como objetivo, buscou-se compreender que conhecimento o professor da EJA tem do pensamento educativo freireano. Para a coleta de dados, utilizou-se de questionário com questão fechada e aberta para o professor manifestar o seu conhecimento. Como fundamentação teórica, este artigo se alicerçou no pensamento Educativo de Paulo Freire e autores que estão em sintonia com seu pensamento. O resultado da investigação revelou que os professores da EJA não tiveram uma formação específica para atuar nessa modalidade de ensino. Para esses professores, o pensamento educativo de Freire é compreendido como importante para pensar o processo pedagógico da EJA, porém, na formação continuada, a ênfase, simplesmente, é dada para a instrumentalização do ensino.
\end{abstract}

Palavras-chave: Educação de Jovens e Adultos; conhecimento freireano; prática educativa.

\begin{abstract}
This article discusses an investigation result conducted with 78 teachers who act in the Education for Young People and Adults in public schools, in Rondonópolis City, Mato Grosso State. The article was generated by the wish for thinking about the teacher pedagogical practice. Its objective was to comprehend which knowledge the Education for Young People and Adults teacher has about the Freirean educational thought. For data collection, we applied a questionnaire with open and closed questions in order to teacher manifests his/her knowledge. Its theoretical fundaments have been based on the Freirean educational thought and the authors who are in agreement with his thought. The investigation result reveals that the Education for Young People and Adults teachers had not have a specific formation to act in this learning modality. For the teachers, the Freirean educational thought is comprehended as important to think about the pedagogical process in the Education for Young People and Adults. Otherwise, in ongoing formation the emphasis is given to the learning instrumentalisation.
\end{abstract}

\footnotetext{
${ }^{1}$ Universidade Federal de Mato Grosso (UFMT), Campus Rondonópolis, Mato Grosso, Brasil.
} 
Keywords: Education for the Young People and Adults; freirin knowledge; educational practice.

Resumen: Este artículo trata de los resultados de una investigación con 78 maestros que trabajan en la educación de jóvenes y adultos en público en la ciudad de Rondonópolis, MT. La investigación fue impulsada por el deseo de reflexionar sobre la práctica pedagógica del profesor. Como objetivo, hemos tratado de entender lo que el conocimiento del profesor de la educación de adultos tiene el pensamiento educativo de Freire. Para recopilar los datos, se utilizó un cuestionario con preguntas cerradas y abiertas para el profesor de expresar sus conocimientos. Como base teórica de este artículo tiene sus fundamentos en el pensamiento pedagógico de Paulo Freire y los autores que están en sintonía con su forma de pensar. Los resultados de la investigación reveló que los maestros de educación de adultos no han tenido una formación específica para trabajar en este tipo de educación. Para estos maestros, el pensamiento educativo de Freire se entiende como importante pensar en el proceso de aprendizaje de la educación de adultos, sin embargo, en la educación continua el énfasis se da simplemente a la instrumentalización de la educación.

Palabras clave: Educación de Jóvenes y Adultos; conocimiento freireano; la práctica educativa.

\section{INTRODUÇÃO}

Passados quase 40 anos da publicação de Pedagogia do Oprimido, cada vez mais o pensamento de Paulo Freire encontra sua atualidade no Brasil e no mundo ante a acentuação de diferentes problemáticas sociais, sobretudo aquelas instadas pela desigualdade e pela injustiça social. Nas palavras de Carlos Alberto Torres (2008), Freire é um educador para além de seu tempo, sua obra é transdisciplinar e transversal, uma vez que entrecorta diferentes áreas de conhecimento e inúmeros campos sociais, como a educação, a filosofia, a saúde, o direito etc.

Basilar à discussão freireana, a noção de conhecimento impulsiona assumir como ato reflexivo a epistemologia da dúvida e da suspeita, como instrumento para a formação da consciência crítica. Pensado para uma sociedade afetada estruturalmente pelo capitalismo, sua teorização da educação é alicerçada na concepção de educação para a justiça social, para a conscientização, pelo respeito e pela humanização na perspectiva de que cada pessoa assuma a condição de sujeito histórico. Não à toa, o avanço conservador que hoje vivemos no país tem se expressado pelo combate violento às ideias desse educador, que o campo educacional elegeu como o patrono da educação brasileira.

Foram os estudos da Pedagogia da Libertação por cerca de 30 anos, que me aproximaram das discussões sobre a educação de jovens e adultos, a qual pretendo discutir centralmente neste texto a partir de resultados de uma investigação sobre "o professor da Educação da EJA e o conhecimento educativo Freireano". 
É importante não apenas permanecer disseminando a teoria desse educador brasileiro em dias de crescimento do fascismo e da violência, como também é importante trazer à reflexão questões acerca dessa modalidade de educação, cuja existência já é a prova de que muito pouco foi feito no país em termos de se garantir a igualdade e a justiça social como projetos de educação.

Assim, a opção por estudar o professor que atua nessa modalidade de ensino foi impulsionada pelo objetivo de compreender que conhecimento os professores possuem acerca do pensamento educativo Freireano, a partir de uma análise dos pressupostos educativos da Pedagogia da Libertação. A pesquisa, de cunho qualitativo, foi realizada com a finalidade de contribuir com a formação permanente centrada na escola, visando ao processo de autotransformação dos professores. Envolveu 78 professores com atividade pedagógica na EJA da rede pública estadual e municipal de Rondonópolis, MT, por meio de realização de entrevista não presencial (com uso de questionário), com questões perpassando a formação acadêmica, a experiência profissional e o conhecimento educativo acerca de Paulo Freire.

O pressuposto ordenador da investigação baseia-se no entendimento de que, para o desenvolvimento do ato pedagógico na EJA, o professor tem, minimamente, algum conhecimento sobre o pensamento educativo freireano. A Leitura da obra de Paulo Freire possibilita ao sujeito se apropriar do conceito de educação problematizadora, por meio de categorias centrais da Pedagogia Libertadora, como: diálogo, construção coletiva do conhecimento, consciência crítica, humanização, educação popular na escola pública, educação da pergunta, educação como prática da liberdade. Do mesmo modo, essa corrente teórica configura-se como contribuição substantiva para a formação permanente centrada na escola, que se constitui como contraponto à concepção de educação bancária (SCOCUGLIA, 2013). A investigação no contexto escolar, sobretudo no aspecto da formação e da atuação docente, também se justifica como instrumento de escuta aos desafios dos professores no desenvolvimento de sua prática pedagógica.

Dessa forma, a pesquisa e a escuta compõem-se como instrumentos mobilizadores da reflexão da prática educativa com a finalidade de problematizar o fazer docente, tencionando produzir uma compreensão do sentido da prática pedagógica no cotidiano da sala de aula. Neste sentido, compreende-se que a mudança da qualidade da educação na EJA passa, necessariamente, pela formação e pelo 
engajamento político do professor na luta por uma educação pela justiça social, enquanto instrumento que habilita ao sujeito fazer uma leitura crítica do mundo do trabalho. Essa teoria da educação se fundamenta na epistemologia da curiosidade e da suspeita que se apresenta como fundamento crítica da pedagogia da opressão. A educação libertadora está inserida em um "eixo transversal que tem na pedagogia da pesquisa seu núcleo irradiador principal" (SCOCUGLIA, 2013, p. 130) e a conscientização como método de formação e transformação do sujeito.

Estruturalmente, este artigo está organizado da seguinte forma: apresenta o pressuposto educativo freireano como aporte teórico para reflexão da investigação, seguido do diálogo como os professores da EJA, destacando o processo metodológico, apresentação dos dados e discussão sobre o resultado da investigação. Por fim, apresenta considerações necessárias para continuar problematizando a formação e prática pedagógica de professores que exercem a docência na EJA.

\section{O PRESSUPOSTO EDUCATIVO FREIREANO}

Para refletir sobre o conhecimento do professor da EJA, no que se refere ao pensamento educativo de Paulo Freire, na perspectiva de problematizar a sua prática pedagógica, apoio-me no entendimento de que a formação e a conscientização são indispensáveis enquanto caminho metodológico para a construção do ato pedagógico enquanto prática social (FREITAS, 2004). No entendimento de Freitas (2004, p. 153), "[...] a consciência crítica permite a assunção dos desafios no trabalho de cada dia, num processo que passa da análise para a denúncia crítica das estruturas desumanizantes, que se desvelam e para o anúncio de novas possibilidades". Assim, em Freire (1979), o educador da EJA pode encontrar suporte necessário para compreender e transformar o mundo, sobretudo para construir um projeto de sociedade, um projeto pedagógico, ancorado ao pressuposto humanista e ao caráter político que reconhece o desejo e a legitimidade do saber popular. Pode encontrar ressonância para tecer a sua prática pedagógica ao pensamento político-pedagógico libertador, enquanto substrato para ordenar a práxis educativa à perspectiva transformadora, porque educar implica tomar posição, apontar uma direção, assumir valores, comprometer-se com o processo de transformação do outro.

A pedagogia de Paulo Freire se estrutura na concepção de educação como ato político, de homem como sujeito, ser inacabado e da história como possi- 
bilidade pautada numa concepção de antropologia da humanização, da amorosidade, da liberdade, da autonomia. É a através do diálogo como essência da educação como prática da liberdade que a assunção cultural do sujeito se realiza. Nesse sentido, pode-se afirmar que a pedagogia freireana é referência para criar uma nova cultura educativa, sobretudo na dimensão de tomada de consciência da afirmação de que educação é princípio fundamental do direito humano. A afirmação de direito "também representa uma herança da Educação Popular na Educação de Jovens e Adultos, a referência (quase obrigatória) à Pedagogia de Paulo Freire, cujo aspecto mais incorporado é a assunção do diálogo como mediador do ato educativo" (FÁVERO, 2013, p. 55). Por isso que, de um modo amplo, para compreender melhor os sujeitos e saberes na educação de jovens e adultos, precisa-se da apropriação do conhecimento da pedagogia estruturada por Freire.

De tal modo, se o professor que trabalha nessa modalidade de ensino necessita ter algum conhecimento desse referencial teórico para desenvolver o processo educativo mais qualificado, o processo educativo, por sua vez, na dimensão da Pedagogia Libertadora, implica o envolvimento da escola, do professor na realidade histórica e social, na perspectiva de desenvolver a consciência crítica do educando. Isso implica, também, afirmar que a atuação de um professor da EJA não está dissociada da compreensão do mundo do trabalho, portanto, do pensamento educativo freireano como marco referencial da educação de adultos.

Dessa forma, a Pedagogia da Libertadora tem o compromisso com a análise de classes, o que, no processo pedagógico, nos chama atenção para a necessidade de ultrapassar o "caráter instrumental e pragmático" presente na prática docente. Para Pinto (2007, p. 63),

[...] a concepção crítica da educação é a única que está dotada da verdadeira funcionalidade e utilidade, pois conduz à mudança de situação do homem e da realidade a qual pertence, em virtude de ser a única que é capaz de oferecer o conteúdo e o método mais eficaz para a instrução da criança e do adulto, tendo em conta aquelas finalidades.

No sentido da conscientização tomada como método, é que se pode compreender que o pensamento educativo e pedagógico de Freire se apresenta como instrumento basilar para pensar e conceber a educação de forma articulada organicamente à dimensão política, cultural e pedagógica. Para existir, viver e conviver 
na sociedade, necessitamos de uma formação que propicie aprendizagem que nos ajude a compreender e nos posicionar criticamente diante do mundo do trabalho. Nesse sentido, concordo com Gadotti (2007, p. 86) ao ressaltar que a Pedagogia do Oprimido produzida por Freire "continua válida não só porque ainda há opressão no mundo, mas porque ela responde a necessidades fundamentais da educação de hoje".

Da mesma forma, é importante pensar que a qualidade da educação está relacionada ao projeto de sociedade, homem e educação ordenado no processo histórico. É mister analisar e compreender que "é sempre a sociedade que dita a concepção que cada educador tem de seu papel, no modo de executá-lo, das finalidades de sua ação, tudo isso de acordo com a posição que o próprio educador ocupa na sociedade" (PINTO, 2007, p. 108). Nessa dimensão, reconhece-se que a educação é sempre uma ação política que reflete as determinações sócio-político-econômicas sistematizadas num tempo histórico. Portanto a práxis educativa exige que o "educador deve compreender que a fonte de sua aprendizagem, de sua formação, é sempre a sociedade" (PINTO, 2007, p. 109) em que está inserido e aquela desejada.

Nesse sentido, é que defendo a Obra de Paulo Freire como referência fundamental para a formação do docente que atua na EJA. O aprofundamento na teoria da educação freireana possibilita aproximar da compreensão do trabalho pedagógico do professor da educação de jovens e adultos. A docência com essa modalidade de ensino requer formação permanente para melhor ampliar a compreensão dos jovens e adultos que são sujeitos de processo educativo, que requer análise significativa, política e pedagógica da luta por direito ao trabalho alicerçado ao pressuposto de uma educação libertadora.

Nesse processo, é que se pressupõe o critério importante para saber que princípios orientam a prática pedagógica do professor e conhecer a fundamentação teórica que ordena a sua concepção de educação, sociedade e homem. Dessa forma, a avaliação sobre a prática pedagógica torna-se mais significativa quando é ouvido o sujeito e verificado o lugar de onde ele fala e faz a educação: a sala de aula da escola pública. Isto implica compreender que o processo de buscar e pensar demoradamente sobre o que pensa e como desenvolve a prática pedagógica no cotidiano da escola constitui um passo metodológico importante para perceber o que e como se faz o ato educativo. 
Penso que a EJA se transforma numa modalidade de ensino significativa somente quando é capaz de explicar o que concebe, o que se vive no processo de mediação da cultura, do conhecimento sistematizado no processo ensino-aprendizagem. Como interlocução teórica para refletir sobre a questão, "além da obra freireana, um marco teórico e prático sempre presente", me pautarei em outros autores que estão em sintonia com o seu pensamento. Para tanto, uma questão singular que deve ser destacada, por um lado, é que a educação escolar é um direito social fundamental para o processo de constituição da cidadania. Por outro lado, que a mudança da concepção de educação e de escola se dá de maneira dialógica, que envolve a práxis educativa vivenciada como coletividade.

Contudo uma mudança teórico-metodológica de caráter significativo só acontece quando mudam de mentalidade os sujeitos que estão lidando diretamente no processo ensino-aprendizagem. Nesse caso, os educadores que atuam na educação de jovens e adultos. O fato relevante enfatizado por Freire (1988, p. 68) é que "ninguém educa ninguém, ninguém educa a si mesmo, os homens se educam entre si, mediatizados pelo mundo". É nesse aspecto que se justifica a pesquisa para saber que conhecimento o professor da EJA tem sobre o pensamento educativo freireano. A intenção da investigação também está subjacente à necessidade de compreender se o professor, no desenvolvimento de sua prática pedagógica, de alguma forma alicerça-se no referencial teórico-metodológico de Paulo Freire. Por outro lado, não se pode perder de vista que a investigação trouxe elementos de relevância acadêmica e científica para uma posterior tessitura de projeto de formação centrada na escola em instituições participantes desta investigação.

\section{DIALOGANDO COMO OS PROFESSORES DA EJA}

Como procedimento metodológico, reportou-se ao aporte teórico da pesquisa qualitativa. A opção por esse caminho fundamenta-se no entendimento de que a abordagem qualitativa está assentada num modelo de análise que possibilita verificar e descobrir as múltiplas facetas de um objeto. Considerando a natureza da pesquisa, adotou-se, como instrumento central para o levantamento de dados, a aplicação de questionário com foco de abrangência na formação acadêmica, experiência profissional e conhecimento do professor da EJA sobre o pensamento educativo de Paulo Freire. 
O primeiro passo da investigação se deu através de um levantamento junto à Secretaria Municipal de Educação e Assessoria Pedagógica da Rede Estadual para saber quantas escolas desenvolviam a modalidade de educação de jovens e adultos na cidade de Rondonópolis. No segundo momento, foi aplicado um questionário a 78 professores que atuam na modalidade EJA na Rede Pública estadual e municipal- em Rondonópolis, MT.

Quanto à formação acadêmica, em nível de graduação, entre os professores investigados que atuam na Educação de jovens e Adultos, destacam-se: 17 professores e professoras formados(as) em Pedagogia, 16 em Letras, 11 em Biologia, 10 em História, nove em Matemática, oito em Educação Física e sete em Geografia.

Quanto à instituição em se formaram, a pesquisa indicou que os professores de História e Geografia cursaram a graduação na UFMT. Dos professores formados em Pedagogia, cinco cursaram a UFMT, e 12 frequentaram diferentes instituições, sendo a maioria privada. Destaca-se que os graduados em Pedagogia têm formação numa segunda licenciatura. Dos professores formados em Educação Física, apenas um fez graduação na UFMT. Cursaram na UFMT também seis professores no curso de Letras, seis licenciados em Matemática e sete em Biologia. Dentre todos os professores investigados, 42 fizeram graduação na UFMT. São, dentre os professores investigados, 51 os que cursaram a graduação na universidade pública, e 27, em instituições privadas.

Quanto ao tempo de formados, classifiquei da seguinte forma: de 1 a 5 anos: 31 professores; de 6 a 10 anos: 18 professores; de 11 a 15 anos: 16 professores; de 16 a 20 anos: quatro professores; mais de 21 anos: cinco professores. Três professores não responderam a esta questão.

Em relação à formação na pós-graduação, dentre os pesquisados, 57 professores têm uma formação ou estavam cursando uma especialização no momento em que a pesquisa foi realizada. Em nível de mestrado, um professor foi formado pelo PPGEdu da UFMT, dois se formaram em Ciencias de La Educación pela Facultad de Ciencias Ambientales (UTCD), no Paraguai, e 17 professores têm apenas graduação. Vale destacar que a especialização perpassa por diversas áreas de formação, algumas seguindo a área da formação inicial na graduação. Porém destaco aqui o que mais me chamou a atenção: oito professores são especialistas em Psicopedagogia, e seis em Gestão, didática e planejamento; seis possuem 
especialização em Metodologia do Ensino; quatro especialistas e dois cursando Metodologia da EJA; cinco em Língua Portuguesa, e dois em Educação Infantil. Das instituições onde cursaram a pós-graduação, 11 fizeram em públicas, 30 em instituições privadas e oito não citaram a instituição.

Sobre a experiência profissional, dos professores investigados, de certa forma, todos têm experiência profissional, embora alguns somente uma experiência mínima de três meses com sala de aula.

Para o diálogo reflexivo sobre os dados da investigação, imitei-me a extrair pontos significativos no questionário. O resultado da investigação está colocado de forma que se evidencie a convergência das respostas apresentada pelos professores, como o objetivo de expressar a síntese do pensamento dos sujeitos. Porém, no espaço de análise dos dados, buscou-se priorizar o extrato de fala do professor e sua relação com o todo.

A questão significativa a ser destacada desde o início da apresentação dos dados é que, antes da experiência do magistério na educação de jovens e adultos, dos 78 professores sujeitos da investigação, somente 22 fizeram uma qualificação específica para atuar nessa modalidade de ensino, os demais não passaram por uma qualificação para o exercício da atividade profissional com EJA.

Em relação ao primeiro encontro do professor com a obra de Paulo Freire, 46 professores relataram que isso ocorreu durante a graduação; 20 em curso de formação; 10 na hora atividade; um destaca que foi indicado por um amigo e outro no magistério.

Na questão do recurso metodológico principal que adota para dinamizar as aulas, um total de 52 professores apontaram o tema gerador. Por outro lado, 20 professores indicaram o livro didático específico para EJA; 16 se reportaram ao uso de texto de revistas; 12 de textos produzidos pelo professor; 12 utilizam a cartilha como recurso; e quatro não responderam. Alguns professores destacaram que adotam mais de um recurso metodológico.

A maioria dos professores que atuam na educação de jovens e adultos conhece as obras de Paulo Freire. Ao serem indagados sobre que obra eles haviam lido integramente de Paulo Freire: 49 disseram que leram Pedagogia da autonomia; 37 leram Pedagogia do oprimido; quatro Importância do ato de ler; dois Educação como prática da liberdade; um Pedagogia da esperança, Educação e mudança, A sombra da mangueira e Professora sim tia não. Por outro lado, cinco 
professores afirmaram que leram apenas trechos da obra e 11 disseram não terem lido nenhuma obra de Paulo Freire.

Quanto à forma e como têm traduzido o pensamento freireano para a prática pedagógica, ordenando sinteticamente as manifestações dos professores, estes convergiram nos seguintes aspectos:

Fazendo com que os conteúdos, a partir da realidade dos alunos sejam significativos para fazer a diferença na vida. Olhar diferente e analisar todo o contexto do aluno. Dialogar mais com o aluno para desperta a criticidade e autonomia. A ideia freireana tem ajudado a compreender e melhorar o atendimento oferecido aos alunos e que possa aprender com isso. Círculo de cultura. Oficinas pedagógicas. Respeitar a experiência de vida de cada um. A ideia do tema gerador e perspectivas da EJA e inserir na aula conteúdo contextualizado. Usando uma metodologia diferenciada de acordo com a bagagem que o aluno já tem. Tenho trazido para minha prática é que a construção do conhecimento se faz de forma coletiva, e devemos criar e recriar uma metodologia de ensino aprendizagem. É o nosso trabalho tem que ser reconstruído/construído constantemente.

É significativo destacar professores investigados, que 11 professores não responderam a essa questão. Pode-se problematizar, nesse aspecto, se o professor tem conhecimento do pensamento educativo de Freire e sua relação com o processo de educação de jovens e adultos, ou até mesmo entender que não é significativo para o desenvolvimento de sua prática pedagógica. Considero que a investigação temática é fundamental com recurso metodológico para a práxis pedagógica do professor.

Na pergunta sobre em que o pensamento de Paulo Freire ajuda a compreender a prática educativa no contexto da EJA hoje, dentre os professores investigados, 10 não responderam à questão. Já para os que responderam, o foco recaiu sobre a questão da realidade, experiência, cotidiano do aluno, visando valorizar e compreender as diferenças de cada ser humano. Assim se manifestaram:

O pensamento de freire é voltado á emancipação e transformação do ser humano. Para o bom relacionamento entre professor-aluno e outros. Ajuda a entender a realidade social e cultural do aluno e a partir daí orientada a prática pedagógica. Os alunos da EJA já trazem suas vivências e experiências de vida que precisa ser valorizados e aproveitados. Trabalhar conteúdo que seja interessante e útil para o dia a dia do educando. Respeito a diversidade 
da aprendizagem, a diversificação das abordagens metodológicas. Que os conteúdos estudados façam parte da vida dos alunos. Coopta e compreender a realidade da EJA nos dias atuais entre o cotidiano e o conteúdo didático. Fazer o aluno pensar entre teoria e prática da vida. Levar conteúdo para a realidade dos alunos, aprender de acordo com eles conhecem.

Na questão que solicitou ao professor citar o conteúdo que é estudado durante a formação continuada de que participa, quatro professores (do total de investigados) não responderam à questão, e um manifestou que não participara da formação continuada na escola.

Na formação continuada na escola, estuda-se uma variedade de conteúdo, muitas vezes dissociados de um projeto de formação centrada na escola. Aqui apresento os pontos mais significativos extraídos no questionário respondido pelos professores:

Sobre Paulo Freire (21); Foco no tema gerador (8). Formação da EJA (8): andragogia, educação e trabalho, aprendizagem significativa, identidade do alunado, metodologia do ensino, educação matemática e prática pedagógica. A importância da tecnologia na prática pedagógica (8). Avaliação diagnóstica (8). Currículos e práticas pedagógicas (7). Planejamento anual (7). PCN e proposta curricular da rede (4). Leitura e produção textual, interpretação (3). Escola organizada por ciclos de formação humana (3). Projetos (3). Reflexão sobre o projeto da escola (2). Metodologia diferenciada (2). Diversidade cultural (2). Educação física (2). Diagnóstico (2).

Para dar dinamicidade ao diálogo, ao longo da reflexão, apresento o extrato da fala dos professores, bem como a ideia convergente do pensamento do conjunto dos professores que foram sujeitos da investigação. Aqui não se trata da convergência do pensamento do todo, mas substrato do pensamento de diferentes professores, com a finalidade de elucidar a proposição da investigação; nesse caso, o professor de educação de Jovens e adultos e o seu conhecimento sobre o pensamento educativo freireano. Para melhor fluir a análise, procuro articular a reflexão com recorte teórico de alguns autores que balizam seu pensamento ao conhecimento de Paulo Freire sobre a prática educativa.

Como ponto de partida do diálogo reflexivo sobre os dados da investigação, aporta-se ao pensamento freireano de educação como um ato político, porque Freire idealizou um sistema de ensino como foco numa proposta pedagógica e política, caracterizado pelo movimento de alfabetização articulada dialeticamente 
na práxis que envolve a educação popular, alfabetização de adultos, educação inclusiva, educação humanizadora e educação de jovens e adultos.

Partindo desse entendimento, é possível afirmar que o professor de EJA, para desenvolver a prática pedagógica significativa, necessita ter um mínimo de conhecimento do pensamento educativo de Paulo Freire, porque essa modalidade requer educar-se para a rebeldia que impulsiona o pensar certo, capaz de discernir o mundo do trabalho e se posicionar política e criticamente sobre a realidade que está inserida.

Nessa perspectiva de educação, é necessário que o professor compreenda que ela tem relação com o contexto histórico e com a determinação sócio-político-cultural do sistema vigente. Contudo, no contexto da prática pedagógica no cotidiano da sala de aula, o educador tem a prerrogativa da liberdade pedagógica que pode estar em convergência ou divergência da determinação que ordena a estrutura da política da educação escolar.

A prática pedagógica do professor não acontece no vazio. A prática está inter-relacionada à concepção de educação, ser humano, compreensão de conhecimento e processo de ensino-aprendizagem apropriada historicamente pelo professor. Isso fica expresso na fala de um professor sujeito da investigação ao afirmar que: a educação é um processo social e a preparação é para vida social, por isso, há necessidade de constante aprendizagem e mudanças no modo de pensar.

Para Jason Mafra (2016), a conectividade e a práxis freireana constituem categoria fundante para o pensar e fazer pedagógico. Fundamentado nesse pressuposto, é que se justifica a compreensão do sentido e o significado do pensamento educativo freireano para o desenvolvimento da prática pedagógica na educação de jovens e adultos. Por isso que o ato educativo e o processo de ensino na EJA não podem ser compreendidos e estruturados obedecendo à lógica de transmissão de conhecimento, porque se trata de um sujeito situado num tempo e espaço que conhece; nesse contexto, a ação pedagógica tem como pressuposto o diálogo. Assim a arena da educação passa ser compreendida como o espaço social que delimita a fronteira entre o ser e o deve ser do desenvolvimento humano, no processo de forjamento da história da atualização e renovação do novo ser humano configurado na existência das crianças.

Contudo é preciso compreender que o "processo educativo tem, para Freire, a tarefa de elucidação dos fatos da realidade a partir da ação consciente sobre 
ela" (ALVES, 2012, p. 114). Porém a libertação que produz a emancipação humana passa por sua reflexão sobre a própria condição de vida e sua inter-relação com as determinações históricas. Nessa perspectiva, é que se pode compreender o que foi dito por um professor que o "pensamento de Freire é voltado à emancipação e transformação do ser humano. Ajuda a entender a realidade social e cultural do aluno e, a partir daí, orientar a prática pedagógica".

Na questão que procurou saber como o professor traduz o significado do pensamento pedagógico freireano para a sua prática pedagógica, extraiu-se, como ponto convergência na resposta dos professores, que o pensamento de Freire inspira a traduzir: uma metodologia diferenciada de acordo com a bagagem que o aluno já tem, respeitada a sua experiência de vida, contextualizando conteúdo para despertar a criticidade. Ensino reflexivo para que o aluno se perceba como sujeito de sua própria vida, buscando sua autonomia.

Já quanto ao recurso metodológico principal utilizado pelo professor para dinamizar as aulas, como referência básica, as opções convergiram para: tema gerador (52). Livro didático específico para EJA (20). Textos de revista (16). Textos produzidos pelo professor (12) e cartilha (12). Somente um professor afirmou que tem trazido para minha prática é que a construção do conhecimento se faz de forma coletiva e devemos criar e recriar uma metodologia de ensino-aprendizagem. O nosso trabalho tem que ser reconstruído/construído continuamente.

Para referenciar, com mais propriedade, a importância do pensamento educativo freireano, no tocante à compreensão do conhecimento, como resultado da prática social, e sua relação com a formação teórico-metodológica docente, fundamento-me no pressuposto teórico que trata da construção coletiva no movimento do método dialógico, o qual alicerça a concepção de educação popular na escola preconizado no pensamento educativo de Freire (1988; 1997; 2000), Gadotti (2007; 2008) e Carvalho (2005). É importante destacar que, nessa perspectiva de educação, o desafio que se coloca para o professor é a necessidade de ser intérprete da cultura de seu tempo, atento à imaginação criadora para compreender, construir e reconstruir a prática, alicerçado ao diálogo problematizador.

A leitura de Freire oferece referencial para envolver-se nesse movimento da práxis educativa de jovens e adultos, porque, no centro da ação pedagógica, está o outro e o diálogo problematizador. No espaço da práxis pedagógica, o pressu- 
posto que move o professor é o compromisso que instiga a recontextualização do conhecimento na perspectiva crítica, dinamizado pela ação de ensinar, aprender e construir saberes, visando à promoção da dignidade humana.

A formação da pessoa na educação formal na visão freireana é inseparável do mundo da vida dos educandos. E, em se tratando da prática pedagógica na EJA, é fundamental entender que o "reconhecimento da humanidade, da dignidade humana dos pobres, negros, dos trabalhadores empobrecidos e oprimidos tem exigido sua escolarização como precondição para o seu reconhecimento como sujeitos de direitos humanos" (ARROYO, 2017, p. 107).

Dessa forma, a educação de jovens e adultos no mundo contemporâneo somente produz qualidade social se estiver comprometida com a produção de outra civilidade. Educação cidadã, educação como prática da liberdade, jamais se coaduna com a lógica da opressão.

Assim, a construção coletiva implica a síntese do diverso porque envolve [...] a síntese da construção do sujeito mediada por um diálogo problematizador, com o objetivo de superar a elaboração particular, convertendo-a numa construção do todo, que vai se configurando em um novo projeto que, posteriormente, se transformará em objeto nuclear de questionamento, visando á construção de uma nova síntese. (CARVALHO, 2005, p. 73).

Nessa perspectiva de educação e aporte metodológico, o resultado da investigação apontou como desafio à modalidade de educação de jovens e adultos a necessidade de pensar e ordenar um projeto de formação que melhor habilite o professor a desenvolver a prática pedagógica problematizadora, cooperativa e solidária que aproxima, promove o diálogo e o reconhecimento do outro.

O resultado da investigação aponta que a maioria dos professores que atuam na modalidade de educação com jovens e adultos não teve formação específica sobre a questão antes de começar as aulas, assim como a formação continuada não tem priorizado conteúdo de formação sobre a temática. Dos setenta e oito professores ouvidos, apenas 21 apontaram que estudam, na formação continuada, texto de Freire.

No contexto da educação de jovens e adultos, compreendo que a obra de Freire, sobretudo a sua concepção teórico-metodológica no campo pedagógico, se transforma num clássico e, ao mesmo tempo, é contemporânea como salto para o futuro. A leitura de sua obra hoje é fundamental para situar-nos historica- 
mente no mundo em transformação, principalmente, para pensar criticamente a realidade sócio-política e apontar caminho possível para um mundo melhor.

A dimensão antropológica da obra de Freire tem foco na existência humana, visando à pedagogia da luta política consubstanciada na valorização de diferentes saberes. Assim, a dialogicidade relacionada à exigência social da amorosidade e humildade transforma-se num ato educativo e pedagógico indispensável para o processo de formação do professor que exerce o trabalho docente com jovens e adultos.

Diante da precariedade da formação de professores para essa modalidade de educação, penso que a formação centrada na escola constitui sempre uma possibilidade de compreensão da prática pedagógica e de novas ações sobre esta. Assim, para dar direção à ação, faz-se necessária a produção de conhecimento alicerçada a uma teoria que possibilita compreender e produzir a crítica ao mundo do trabalho.

Dessa forma, a formação passa, necessariamente, pela compreensão da condição humana que tenciona a prática docente enquanto práxis pedagógica, transformadora da ação na sua relação com o processo ensino e aprendizagem. Isso implica refletir sobre os saberes pedagógicos como produto do desenvolvimento do trabalho coletivo do educador no contexto da escola, porque "a escola não é só um lugar para estudar, mas para se encontrar, conversar, confrontar-se com o outro, discutir, fazer política" (GADOTTI, 2008, p. 92), bem como, o lugar do confronto entre o instituído e instituinte.

Logo, na formação de professores para a Educação de Jovens e adultos, carece entender que,

[...] o importante é perceber que o fundamental é sermos dialéticos em nosso agir político; pensar dialeticamente; atuar dialeticamente; em outras palavras, ser, dialeticamente ou, o que é o mesmo, ser científicos e históricos, e assim poderemos somar, apoiar orientar e ajudar no desenvolvimento da verdadeira alternativa histórica que a classe proletária está construindo. (NUNEZ HURTADO, 1992, p. 122).

O fato notório é que a atividade da coletividade do ser humano impacta na forma e no processo de pensar de cada sujeito, conduzindo-o ao movimento da reflexão e da construção do conhecimento. Mas é importante destacar que, embora o esforço da tessitura desse processo apareça no âmbito da individualidade 
do sujeito, o que constitui a sua autonomia, esse movimento tem implicação na individualidade humana e da sua consciência desse processo. A questão é que o modo de ser de cada sujeito vá construindo a sua forma de percebê-lo na relação com o outro eu e o mundo social.

Nessa perspectiva, é que posso compreender que a produção qualitativa do conhecimento pedagógico passa pela reflexão da e sobre a própria prática, como enfatiza Freire (1997). É o movimento de reflexão que leva o educador a sair da realidade e voltar a ela com outro olhar. Por isso que, na prática pedagógica na educação de jovens e adultos, não pode prescindir a solidariedade de classe como instrumento de identificação e mobilização do ato educativo.

No sentido da reflexão proposta, isso implica pensar que o ato pedagógico se constitui como ato de conscientização, porque leva a pensar sobre o que se faz e pensar a própria realidade do mundo pedagógico em que se está inserido. É a ação refletida e colocada a serviço de uma finalidade. Nesse caso, a atuação docente frente à educação de jovens e adultos, para produzir uma ação significativa, precisa estar alicerçada à concepção crítica da educação, na qual se define o modo crítico de pensar, porque

[...] é a única que está dotada da verdadeira funcionalidade e utilidade, pois conduz à mudança da situação do homem e da realidade à qual pertence, em virtude de ser a única que é capaz de oferecer o conteúdo e o método mais eficaz para a instrução da criança e do adulto, tendo em conta aquelas finalidades. (PINTO, 2007, p. 63).

Enfim, significa estar atento à necessidade de pensar a ação docente que produza uma aprendizagem significativa, na perspectiva da educação de qualidade social, que, sem dúvida, implica a recriação permanente da própria prática. Para a produção do conhecimento e de uma prática pedagógica de melhor qualidade na contemporaneidade, obrigamo-nos a revisitar os teóricos bibliográficos no sentido de procurar inspiração, vozes, eco do passado que possam nos ajudar a compreender e aprofundar os problemas que nos incomodam no presente. 0 perscrutar a história procurando buscar vozes nos teóricos não significa encontrar respostas prontas, mas inspiração para que possamos dialogar e problematizar a realidade social, educativa e prática pedagógica no cotidiano da escola. Diante do mundo contemporâneo eivado de contradição, antagonismo, o ser humano, sobretudo o educador, não pode "demitir-se do direito de pensar". 
Como sujeito histórico da educação, penso que, na questão da educação de jovens e adultos, o pensamento de Freire constitui uma referência teórico-metodológica necessária, porque enfatiza a questão da libertação-conscientização como central da educação para a emancipação do sujeito que requer a educação nessa modalidade; pensar, refletir o universo cultural que envolve o seu imaginário simbólico na ação cotidiana para transformá-lo.

Para a ação docente na sala de aula, metodologicamente o passado, a história, não pode ser o ponto de partida, tampouco o ponto de chegada para a análise da realidade cotidiana. O passado - base teórica - aponta, irradia luzes e se apresenta como questionamento necessário entre o instituído e o instituinte para a recriação e ordenação dos saberes pedagógicos cotidianos.

Para que o ensino se transforme em significativo, "o aluno precisa construir e reconstruir o conhecimento a partir do que faz" (GADOTTI, 2008, p. 94). A educação de jovem e adulto constitui-se num espaço para ensinar, aprender, pesquisar, sobretudo para reinventar, organizar e construir conhecimento e aprendizagem. Nessa dimensão, a obra de Freire torna-se um instrumento teórico-metodológico fundamental para o envolvimento nesse processo.

O resultado da pesquisa levou-nos a compreender que, no âmbito metodológico, o trabalho pedagógico com a Educação de Jovem e Adulto passa pela construção coletiva,

[...] já que ela se configura num instrumento fundamental de diálogo com as práticas, onde cada sujeito que participa do processo de construção do conhecimento, possa desenvolver a sua individualidade, mas reconhecendo que a sua construção pessoal é mediada por múltiplas interferências. A construção coletiva é o espaço que permite que cada agente social o compreenda enquanto sujeito comunicante, e que a sua formação acontece mediante o encontro com as diferentes vertentes que a realidade oferece. (CARVALHO, 2005, p. 57).

Levou-nos a entender a necessidade de reafirmamos a contribuição do "referencial teórico-metodológico freireano" para o atual contexto da escola pública comprometida com a busca de novos caminhos de ação política pedagógica capaz de desenvolver a educação de qualidade social. Nessa perspectiva, penso que é

[...] o espaço fundamental para uma prática educativa, orientada pela construção coletiva e trabalho enquanto princípio educativo, é o da escola pública 
popular. Neste espaço, o professor e o aluno compreendem que são sujeitos histórico-sociais, que vivem num contexto sociocultural, relacionando-se com as diferentes culturas. (CARVALHO, 2005, p. 57).

Para finalizar, em se tratando de uma proposta pedagógica e política,

Paulo Freire continua um paradigma válido e atual para a Educação Popular, sobretudo no que se refere a sua epistemologia, embasada na compreensão crítica da relação seres humanos-mundo. A influência de sua concepção teórico-metodológica no campo pedagógico é justamente o que faz do conjunto da obra freireana um clássico. (PACHECO JUNIOR; TORRES, 2009, p. 20-1).

Analisando a fala dos professores sujeitos da investigação, pode-se afirmar que o pensamento de Freire continua como referência significativa para pensar o processo pedagógico da Educação de Jovens e Adultos. Porém é importante questionar que, embora os professores indicando que conhecem e leram algumas obras de Freire, na formação continuada a ênfase recai sobre a ótica da instrumentação do ensino. Portanto, frente ao contexto da capacitação do professor para o exercício da docência na educação de jovens e adultos, faz-se necessário problematizar a importância dada a essa modalidade de ensino e a política de formação desenvolvida na escola. Pensar a educação de jovens e adultos fundamentada ao pensamento educativo freireano, além do compromisso do professor, requer o delineamento de uma política pública que possibilite a formação permanente de professor comprometida com a reflexão e transformação da própria prática.

Mas, para o pensamento de Barcelos (2012, p. 26), a "educação para ser educação precisa estar envolvida com o desejo de instituição de pessoas que não só busquem um posto de trabalho, mas que estejam buscando a realização de seus desejos e mesmo de seus sonhos", na perspectiva de uma educação que se estrutura na crítica, emancipação, liberdade e autonomia. Essa concepção tem relação com o pensamento educativo e pedagógico de Paulo Freire (1997) quando enfatiza que o ato de ensinar exige criticidade, respeito aos saberes dos educandos e coerência entre o pensar e fazer; por isso que a Educação de Jovens e Adultos só produz a qualidade social se estiver comprometida com a promoção da dignidade, criatividade e liberdade humana. Para que isso se transforme numa ação pedagógica significativa, 
[...] é preciso e até urgente que a escola se vá tornando um espaço acolhedor

e multiplicador de certos gostos democráticos como o de ouvir os outros, não por puro favor mas por dever, o de respeitá-los, o da tolerância, o do acatamento ás decisões tomadas pela maioria a que não falte contudo o direito de quem diverge de exprimir sua contrariedade. $O$ gosto pela pergunta, da crítica, do debate. (FREIRE, 2000, p. 89).

Nesse cenário, o professor da Educação da EJA tem a função e um papel muito importante de criar as condições pedagógicas para promover o processo de ensino e aprendizagem. Espera-se que seja mobilizador, mediador e problematizador do conhecimento para que o estudante possa construir e reconstruí-lo a partir do que faz. Nesse ponto, a pedagogia do diálogo que Freire pensou e praticou torna-se para nós, hoje, um aporte teórico-metodológico para reinventá-lo cotidianamente em nossa práxis pedagógica, porém, na perspectiva da pedagogia do oprimido, alicerçado na utopia libertadora. Porque, como bem afirma o próprio Freire (1997, p. 78)

[...] especificamente humana a educação é gnosiológica, é diretiva, por isso política, é artística e moral, serve-se de meios, de técnicas, envolve frustrações, medos, desejos. Exige de mim, como professor, uma competência geral, um saber de sua natureza e saberes especiais, ligados á minha atividade docente.

\section{CONSIDERAÇÕES NECESSÁRIAS}

A pesquisa levou-me a compreender que a Educação de Jovens e Adultos é uma modalidade de educação imperativa ainda para o contexto social contemporâneo, por isso que, declara Afonso Scocuglia (2013, p. 163),

[...] tem recebido nas últimas décadas a atenção em todo o mundo em função das mudanças sociais, dos caminhos da globalização e das mudanças nos processos do trabalho. As questões que perpassam a juventude, as necessidades da sociedade letrada e da informação, a relevância da diversidade cultural, inclusas as questões indígenas na América Latina, por exemplo, ganham novas leituras e novas ênfase analíticas.

Partindo do que foca a reflexão acima, percebe-se que para problematizar a educação, a formação de professores e a pesquisa, o pensamento de Freire permanece atual com balizador no processo de conscientização na transição da contemporaneidade. 
Por outro lado, destaco que o resultado da investigação incita a pensar e problematizar se a atividade pedagógica do Professor da EJA se alicerça no pensamento educativo freireano. Os dados apresentados possibilitaram inferir que, frente a pouca indicação de leitura da obra de Paulo Freire durante a formação continuada, o trabalho docente com a EJA tem pouca referência ao processo teórico-metodológico freireano.

Porém a investigação trouxe elementos significativos para pensar a política de formação de professores que atuam na EJA, tendo em vista que a prática pedagógica com essa modalidade de educação requer que o professor tenha formação alicerçada na teoria da educação produzida por Freire, a fim de que ele possa compreender o estudante como sujeito, na perspectiva do envolvimento no processo de autotransformação da realidade social.

A práxis pedagógica com a EJA mobiliza o professor para o diálogo com o outro, por isso precisa entender que "o encontro com outro e a convivência com a diversidade são de extrema importância" para o trabalho pedagógico de qualidade social. Da mesma forma, ele precisa entender que "as pessoas é que são o centro da escola, protagonistas da ação educativa que nela é desenvolvida" (GOELZER; OLIVEIRA; SANTOS, 2015, p. 59).

Na perspectiva do pensamento pedagógico Freireano, a atividade pedagógica é sempre uma partilha com o estudante. Compreendo que, para o desenvolvimento de atividade educativa com EJA, é fundamental que o professor se envolva com a formação permanente, centrada na escola como instrumento de mediação para constituição de uma docência de melhor qualidade. A proposta político-pedagógica de Freire é desafiadora, porém, para transformar a sua prática pedagógica numa ação mobilizadora que impulsiona para a emancipação humana, "não basta respeitar os saberes dos alunos. Necessário se faz explorar com os alunos as reais necessidades de alguns desses saberes relacionando-os com o ensino e aprendizagem" (CARVALHO; SANTOS, 2015, p. 24).

Educar na visão da pedagogia Libertadora freirena implica que o professor necessita assumir como sujeito e pesquisador do contexto da prática, porque o ser humano está incessantemente em busca, em processo. E a educação, caracteriza-se nesse movimento como prática permanente da formação da pessoa. Ao professor no contexto da EJA compete criar as condições pedagógicas que 
impulsionam o educando a envolver na atividade de reflexão e apropriação de ferramenta conceitual para construção de conhecimento.

Para melhor entender a importância da formação como determinação para a qualidade da educação, pode-se verificar o que declara Freire (1997, p. 43-4),

[...] por isso é que, na formação permanente dos professores, o momento fundamental é o da reflexão crítica sobre a prática. É pensando criticamente a prática de hoje ou de ontem que se pode melhorar a próxima prática. $\mathrm{O}$ próprio discurso teórico, necessário á reflexão crítica, tem de ser de tal modo que quase se confunda com a prática.

Por isso que a formação alicerçada no pensamento educativo e pedagógico freireano requer "rigorosidade metódica, pesquisa e respeito aos saberes dos educandos" (FREIRE, 1997). Assim, no espaço da escola, a formação pensada tomando como pressuposto o diálogo reflexivo da e sobre a prática, desafia e estimula o professor a envolver-se no processo de construção

[...] a partir da observação e reflexão sobre o seu cotidiano para solucionar problemas, orientando-se por uma atitude investigativa. Assim, a pesquisa passa a ser um componente fundamental para o desenvolvimento profissional do professor, a partir da articulação entre teoria e práticas educativas. (JARDELINO; ARAÚJO, 2014, p. 149).

A teoria da educação de Freire contribui com a formação do professor para que ele possa se inventar e reinventar como sujeito de sua prática. Porém, para o desenvolvimento do trabalho docente com qualidade social, é fundamental criar as condições pedagógicas para que os estudantes possam envolver-se no processo de ensino-aprendizagem. É importante que o professor entenda que a "EJA vinculada ao trabalho se revela como caminho determinante para articular as exigências de desenvolvimento econômico e qualidade social" (SCOCUGLIA, 2013, p. 168). Nesse ponto, pode-se inferir que a leitura de Freire é indispensável para a formação permanente centrada na escola. A pedagogia freireana parte do princípio de que o outro é pessoa e sujeito de direito, por isso se transforma instigante para educação de jovens e adultos como sujeito histórico-social.

O desenvolvimento do ato pedagógico alicerçado no pensamento de Freire implica compreender e ter, na pedagogia da pesquisa, o núcleo irradiador principal que estimula a reflexão crítica sobre a prática. Compreendo que a pesquisa é condição para formação de professores, porque instiga ao ato de descobrir e 
desvelamento do mundo. Possibilita ampliar a compreensão da realidade e complexidade humana, bem como a produção de novos conhecimentos.

A organização do trabalho pedagógico, em conformidade com o conhecimento manifesto na obra de Paulo Freire, exige permanente busca, reinvenção e postura crítica da práxis para produzir conhecimento à luz de novos desafios do mundo contemporâneo. Em síntese, o conhecimento educativo e pedagógico de Freire é fundamento para formação do professor, porque tenciona, problematiza e instrumentaliza ao professor a análise e compreensão de que a sua prática e formação teórica é permanente.

\section{REFERÊNCIAS}

ALVES, Solange Maria. Freire e Vigotski: um diálogo entre a pedagogia freireana e a psicologia histórico-cultural. Chapecó, SC: Argos. 2012.

ARROYO, Miguel G. Passageiros da noite: do trabalho para a EJA: itinerários pelo direito a uma vida justa. Petrópolis, RJ: Vozes. 2017.

BARCELOS, Valdo. Educação de jovens e adultos: currículo e práticas pedagógicas. 3. ed. Petrópolis, RJ: Vozes, 2012.

CARVALHO, Ademar de Lima. Os caminhos perversos da educação: a luta pela apropriação do conhecimento no cotidiano da sala de aula. Cuiabá, MT: EDUFMT, 2005.

CARVALHO, Ademar de Lima; SANTOS, Terezinha de F. Ávila. A formação docente e o pensamento educativo freireano. In: SILVA, Adelmo Carvalho da; CARVALHO, Ademar de Lima; CARDOSO, Cancionila Janzkovski (Org.). Formação docente e práticas educativas na escola. Cuiabá, MT: EDUFMT, 2015. p. 15-27.

FÁVERO, Osmar. Paulo Freire, movimentos sociais e educação de Jovens e Adultos. In: STRECK, Danilo R.; ESTABAN, Maria Teresa (Org.). Educação popular: lugar de construção social coletiva. Petrópolis, RJ: Vozes, 2013. p. 49-63.

FREIRE, Paulo. Professora sim tia não: cartas a quem ousa ensinar. 10. ed. São Paulo: Olho D’Água, 2000.

. Pedagogia da autonomia: saberes necessários à prática educativa. São Paulo: Paz e Terra, 1997.

. Pedagogia do oprimido. 18. ed. Rio de Janeiro: Paz e Terra, 1988.

. Educação e mudança. 20. ed. Rio de Janeiro: Paz e Terra, 1979.

FREITAS, Ana Lúcia Souza. Pedagogia da conscientização: um legado de Paulo Freire à formação de professores. 3. ed. Porto Alegre: EDIPUCRS, 2004. 
GADOTTI, Moacir. Reinventando Paulo Freire na escola do século XXI. In: TORRES, Carlos Alberto et. al. Reinventando Paulo Freire no século XXI. São Paulo: Instituto Paulo Freire, 2008.

2007.

A escola e o professor: Paulo Freire e a paixão de ensinar. São Paulo: Publisher,

GOELZER, Juliana; OLIVEIRA, Luiz Renato de; SANTOS, Caroline da Silva dos. Sobre escutar crianças, adolescentes, jovens e adultos na escola: desafios e possibilidades para a auto(trans)formação de professores. In: HENZE, Celso Ilgo; TONIOLO, Joze Medianeira dos Santos de Andrade (Org.). Dialogus: círculos dalógicos, humanização e auto(trans) formação de professores. São Leopoldo, RS: Oikos, 2015. p. 51-61.

JARDILINO, José Rubens Lima; ARAÚJO, Regina Magna Bonifácio de. Educação de Jovens e Adultos: sujeitos, saberes e práticas. São Paulo: Cortez, 2014.

MAFRA, Jason Ferreira. Paulo Freire, um menino conectivo: conhecimento, valores e práxis do educador. Brasília: Líber Livro, 2016.

NUNEZ HURTADO, Carlos. Educar para transformar, transformar para educar: comunicação e educação popular. Petrópolis, RJ: Vozes, 1992.

PACHECO JUNIOR, Israel; TORRES, Michelangelo Marques. Atualidade do pensamento de Paulo Freire na educação popular. In: ASSUMPÇÃO, Raiane (Org.). Educação popular na perspectiva freireana. São Paulo: Instituto Paulo Freire, 2009.

PINTO, Álvaro Vieira. Sete lições sobre educação de adultos. 15. ed. São Paulo: Cortez, 2007.

SCOCUGLIA, Afonso Celso. A teoria só tem utilidade se melhorar a prática: as propostas de Paulo Freire. Petrópolis, RJ: De Petrus et Alii; Rio de Janeiro: FAPERJ, 2013.

TORRES, Carlos Alberto. Novos pontos de partida da pedagogia política de Paulo Freire. In: TORRES, Carlos Alberto et al. Reinventando Paulo Freire no século XXI. São Paulo: Instituto Paulo Freire, 2008. p. 41-51.

\section{Sobre o autor:}

Ademar de Lima Carvalho: Possui graduação em Filosofia pela Universidade Católica Dom Bosco (1982); graduação em Pedagogia (1988) e mestrado em Educação (1995) pela Universidade Federal de Mato Grosso (UFMT); doutorado em Educação Brasileira (2002) pela Universidade Estadual Paulista Júlio de Mesquita Filho (UNESP). É professor Associado IV da UFMT. Tem experiência na área de Filosofia da Educação, Pedagogia: teoria da educação e prática pedagógica, Educação Pública, com foco de atuação na docência, e pesquisa nos seguintes 
temas: Fundamentos da educação/ Organização do Trabalho Pedagógico na Escola: coordenação, Projeto político pedagógico e gestão democrática / Natureza da Prática Docente / Construção do Conhecimento Pedagógico/Formação permanente de professor centrada na escola/ Pedagogia e prática pedagógica na sala de aula. E-mail: ademarlc@terra.com.br

\section{Recebido em abril de 2017}

Aprovado em novembro de 2017 